\title{
Um corte na alma: como parturientes $e$ doulas significam a violência obstétrica que experienciam
}

\author{
Juliana Sampaio' (iD) 0000-0003-0439-5057 \\ Tatiana Lopes de Albuquerque Tavares ${ }^{2}$ (iD) 0000-0003-0543-4185 \\ Thuany Bento Herculano ${ }^{3}$ (iD) 0000-0002-9218-9415
}

'Universidade Federal da Paraíba, Centro de Ciências Médicas, Departamento de

Promoção da Saúde, João Pessoa, PB, Brasil. 58051-900

${ }^{2}$ Universidade Federal da Paraíba, Centro de Ciências Jurídicas,

Santa Rita, PB, Brasil. dcj@ccj.ufpb.br

${ }^{3}$ Universidade Federal da Paraíba, Centro de Ciências Médicas, João Pessoa, PB,

Brasil. 58051-900

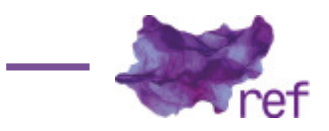

Resumo: Neste artigo busca-se entender como mulheres (parturientes e doulas) significam as violências obstétricas que vivenciam. O estudo foi realizado a partir da análise das narrativas de três parturientes e duas doulas a respeito da assistência experienciada na maior maternidade da Paraíba em 2017. As cinco mulheres frequentavam as reuniões de um grupo de gestantes, nas quais eram trocadas informações sobre a assistência ideal a partir dos preceitos da humanização do parto e nascimento. Informação e empoderamento, elementos cruciais na pauta da humanização, não foram suficientes para garantir que essas mulheres não fossem violentadas. Pelo contrário, elas vivenciam sua invisibilização como sujeitos, ao passo que seus corpos são objetificados. A informação, que deveria ter sido ferramenta para garantia de direitos, funcionou e instrumentalizou a violência.

Palavras-chove: Violência de gênero; Humanização do parto; Obstetrícia; Assistência perinatal.

A Slash in The Soul: How Parturients and "Doulas" Mean the Obstetric Violence that Experience

Abstract: This article aims to understand how women (parturients and doulas) mean the obstetric violence they experience. The study was carried out from the analysis of the narratives of three parturients and two doulas about the assistance experienced in the largest maternity hospital in Paraíba in 2017. The five women attended the meetings of a group of pregnant women, in which information was exchanged on the ideal assistance from the precepts of the humanization of childbirth and birth. Information and empowerment, crucial elements in the humanization agenda, were not enough to ensure that these women were not violated. On the contrary, they experience their invisibility as subjects, while their bodies are objectified and transformed into instruments for teaching. The information, which should have been a tool for guaranteeing rights worked to instrumentalize violence.

Keywords: Violence Against Women; Humanizing Delivery; Obstetrics; Perinatal care.

\section{Introdução}

A violência obstétrica pode ser definida como sendo a violência cometida por profissionais de saúde contra a mulher durante o processo gravídico-puerperal, através da apropriação do seu corpo e dos seus processos reprodutivos, expressa por meio de um trato desumanizador, abuso da medicalização e patologização dos processos naturais (Charles Dalcanale TESSER et al., 2015; Aline Barros de SOUZA et al., 2017). 
Toques vaginais sem permissão ou sequenciados, realização de episiotomia sem consentimento e/ou de modo protocolar, manobra de Kristeller, uso rotineiro de ocitocina, impedimento para se alimentar ou se movimentar ou, ainda, utilização de frases e gestos que possam inferiorizar a mulher ou afetá-la psicologicamente são algumas das condutas consideradas como violência obstétrica. Essas condutas desnecessárias e arriscadas são violações ao direito da mulher à sua integridade corporal (TESSER et al., 2015; Ligia Moreiras SENA; TESSER, 2016; Maria Luiza Gonzalez RIESCO, 2014; Melania AMORIM et al., 2017).

A imposição autoritária e não informada desses procedimentos atenta contra o direito à condição de pessoa e está calcada na não aceitação da autonomia da mulher sobre o seu corpo e suas vontades durante a gravidez, parto, pós-parto ou situação de abortamento (Thamiza da Rosa dos REIS et al., 2017; Carmen Simone Grilo DINIZ et al., 2016).

Como forma de enfrentamento dessa realidade, mulheres grávidas, ativistas do movimento da humanização do parto, doulas e profissionais de saúde interessados no tema passaram a se reunir em grupos virtuais ou físicos para compartilhar informações baseadas em evidências científicas e trocar experiências de atuação em um novo modelo assistencial (SENA; TESSER, 2016).

Quando falamos sobre a ocorrência de violência obstétrica, sobretudo em maternidades públicas, estamos falando de uma violência de gênero perpetrada pelo Estado através de instituições por ele constituídas, de uma equipe profissional por ele contratada, contra mulheres que deveriam ser, pelo mesmo Estado, protegidas e não violentadas (DINIZ, 2005). Estas violações dos direitos das mulheres são mais uma expressão das iniquidades presentes na sociedade machista e patriarcal na qual estamos inseridos (Heleieth SAFFIOTI, 2015).

Diante do exposto, pretendemos analisar a violência obstétrica como uma forma de violência de gênero (SAFFIOTI, 2001) ocorrida na principal maternidade pública do estado da Paraíba, com o objetivo de entender como as mulheres, parturientes e doulas vivenciam e significam essa violência.

\section{Abordagem metodológica}

A motivação para esta pesquisa se deu ao longo de três anos de acompanhamento dos encontros em uma roda de apoio à gestação, parto e maternagem, chamada Gestar e Maternar, que possui um caráter voluntário, com reuniões quinzenais, nas quais mulheres se reúnem para trocar experiências de parto e maternagem dos filhos, buscar informações sobre as altas taxas de cesarianas no país, sobre as cesáreas agendadas por conveniência médica, entre outras facetas do sistema obstétrico brasileiro.

A partir desta experiência, foram levantados os relatos de várias mulheres que compartilharam suas histórias com o grupo no ano de 2017. Na sistematização desses relatos, foram selecionadas três parturientes, que aqui chamaremos por Quitéria, Celina e Dandara, que haviam sido atendidas no momento do parto na maternidade pública " $X$ " e ainda duas mulheres, aqui reconhecidas como Dora e Leolinda, que atuam como doulas voluntárias na mesma instituição.

As três parturientes tinham entre 24 e 29 anos, se declaravam negras ou pardas, e primíparas; duas tinham ensino superior completo e outra ensino médio completo. Dentre as duas doulas, uma tinha 32 anos, se declarava negra, sem filhos, e com ensino superior completo, e a outra tinha 24 anos, se declarava branca, sem filhos, e com ensino médio completo.

Com vistas a preservar a confidencialidade da pesquisa, os nomes verdadeiros de todas essas mulheres serão mantidos em sigilo. O critério utilizado na escolha das entrevistadas priorizou as mulheres que relatavam ter sofrido ou presenciado violência obstétrica na citada maternidade.

A escolha da maternidade " $X$ " se deu em virtude de se tratar da principal maternidade do estado da Paraíba, visto que seu caráter público termina por ensejar uma maior preocupação no tocante à realização, por parte do Estado, de quaisquer condutas que possam violentar as mulheres. Além disso, é um hospital-escola e, dessa forma, também é responsável pela formação de futuros profissionais de saúde. A maternidade escolhida é pioneira no estado na atuação de doulas voluntárias em apoio às parturientes, sendo estas doulas formadas por um curso oferecido pela própria instituição. Após a realização e aprovação no curso, as doulas voluntárias passam a atuar na maternidade no apoio às puérperas ali atendidas.

A doula foi escolhida como um ator social relevante para compor o presente trabalho, ao lado dos relatos experienciados pelas parturientes, devido à proximidade que elas estabelecem com as mulheres neste momento em particular, buscando um atendimento que priorize a vontade da mulher e lhe garanta apoio e a preservação de seus direitos no momento do parto.

Reconhecemos neste trabalho doulas enquanto mulheres que atuam como acompanhantes leigas treinadas. A palavra "doula" tem origem grega e significa "mulher que serve", e hoje se refere à profissional com treinamento específico sobre fisiologia do parto normal, métodos não farmacológicos para alívio da dor, cuidados pós-natais e aleitamento materno (Míriam Rêgo de Castro LEÃO; Marisa Antonini Ribeiro BASTOS, 2001).

Por trabalharem de forma voluntária, não mantendo vínculo profissional ou institucional com a maternidade, supomos que as doulas estejam menos suscetíveis ao receio de sofrer 
retaliações por não concordar com a conduta de algum dos profissionais de saúde. Como mencionado por uma doula: "Nós somos a sociedade civil lá dentro. Estamos olhando pela mulher, nosso interesse é a mulher, resguardar os direitos dela" (Dora, doula).

As cinco narrativas utilizadas neste trabalho foram provocadas por um roteiro semiestruturado, que nos serviu apenas de parâmetro norteador para a produção das narrativas. As entrevistas foram realizadas em lugares diversos, escolhidos pelas personagens desta pesquisa, atendendo à necessidade de cada uma de comodidade e privacidade.

Esta pesquisa está pautada no paradigma qualitativo interpretativo, no qual os significados atribuídos à experiência são explorados conforme o olhar da própria pessoa que a vivenciou. Tais experiências são acessadas mediante interação próxima entre o pesquisador e os sujeitos da pesquisa (Maria Cecília de Souza MINAYO et al., 2008). O método de pesquisa foi a análise da narrativa, o qual é desenvolvida mediante cinco fases: acessar, contar, transcrever, ler e analisar a experiência (Catherine Kohler RIESSMAN, 2008). A partir disso, foi possível identificar a recorrência de ideias em relação à experiência vivida e elaborar categorias descritivas que representassem tais relatos.

A pesquisa foi aprovada pelo Comitê de Ética em Pesquisa do Centro de Ciências da Saúde da Universidade Federal da Paraíba (CAAE - 67650617.0.0000.5188). As diretrizes que regulamentam as pesquisas envolvendo seres humanos, aprovadas pela Resolução do Conselho Nacional de Saúde (CNS) número 466/2012, foram seguidas em todas as etapas deste estudo.

\section{"Aqui você não tem opção": sobre o lugar destinado à mulher, na hora do parto, nas maternidades}

Os relatos produzidos pelas mulheres no decorrer desta pesquisa terminaram por descortinar condutas que vão além das já descritas no rol das violências obstétricas. Para além das episiotomias sem consentimento, das manobras ou procedimentos invasivos e violentos, das frases ameaçadoras e de cunho machista, esses relatos estavam permeados de descrédito, desrespeito, invisibilidade e objetificação.

Foi possível identificar nas narrativas as marcas do poder decorrente da relação entre mulheres e maternidade; poder intrínseco à figura dos(as) obstetras, mas que se ramifica para os demais componentes da equipe de saúde. Uma relação que, não por acaso, assumia um caráter disciplinar e hierárquico, de maneira a evidenciar o lugar de subserviência dessas mulheres perante a instituição.

A objetificação do corpo da mulher, a invisibilidade dela como sujeito de direitos, a impossibilidade de exercer sua autonomia dentro do ambiente hospitalar e a constatação de um ensino médico que termina por não produzir uma relação respeitosa entre o produtor do cuidado em saúde e o usuário são elementos que compõem este cenário e serão apresentados aqui.

\section{Objetificação e invisibilidade}

Eu não era uma pessoa, eu era mais uma que estava ali parindo dentre tantas outras que foram e que iam. Era padrão, automático, o tratamento com todas era esse. Ninguém olhava nos olhos, ninguém perguntava se eu estava bem, ninguém perguntava nada. Eu não era uma pessoa, era uma coisa, um objeto (Dandara, parturiente).

Considerando o contexto em que a figura da mulher está inserida, que tenta lhe extirpar seus direitos e espaço social, esse processo de despersonalização da mulher clarificado na fala de Dandara começa a ser construído desde a admissão na maternidade, quando é submetida ao "cerimonial de internação" - caracterizado pela separação da família, remoção de roupas e de objetos pessoais, ritual de limpeza e restrição alimentar e de movimentação (Elizabeth Eriko Ishida NAGAHAMA; Silvia Maria SANTIAGO, 2005, p. 656)

Assim que eu cheguei na maternidade a minha mãe, minha irmã e o pai da minha filha foram barrados. Eu sentindo muitas dores e o ser humano na minha frente dizendo que tinha que preencher a ficha. [...] Me pegaram no meio do corredor, não falaram nada, me puxaram pra uma sala, todo mundo com roupa igual, e aí começaram: deita aqui, tira a roupa [...] Enquanto eu estava tendo uma contração, tiraram minha roupa, tiraram tudo que estava em mim, colocaram uma bata, me deitaram na cama. [...] (Celina, parturiente).

A padronização obtida com as roupas (batas) iguais e retirada de objetos pessoais faz com que a mulher perca a sua individualidade e passe a ser uma "paciente" daquele hospital. Você entra, responde perguntas, troca de roupa, cumpre os protocolos. A partir daquele momento, a mulher não é mais dona do seu corpo, de suas vontades. "A atenção foi organizada como numa linha de produção e a mulher transformou-se em propriedade institucional" (NAGAHAMA; SANTIAGO, 2005, p. 656).

E como que em tom de sincronicidade, essa concepção de linha de produção trazida pelas autoras é descrita por Celina quando ela afirma: "eles simplesmente fazem como se você 
fosse um objeto e estivesse passando por processos numa indústria". Foi assim que ela se sentiu: como um objeto em uma fábrica. Simplesmente passando por uma linha de produção, na qual não lhe era permitido opinar, discordar. Era preciso ser apenas "paciente".

No hospital, a proliferação de rituais em torno de um evento fisiológico e natural, conhecidos como "procedimentos de rotina para atenção ao parto", acaba por perpetuar os valores nucleares da nossa sociedade (Robbie DAVIS-FLOYD, 1992). Nela, o sucesso da assistência ao parto é baseado na ciência, resultado direto do uso intensivo da tecnologia e aplicado em instituições fortemente influenciadas pela ideologia do patriarcado (DAVIS-FLOYD; Gloria SAINT JOHN, 1998).

A assunção do saber do parto pela medicina, com a ida das mulheres para parir nos hospitais, trouxe uma institucionalização não apenas do parto, mas também dos corpos dessas mulheres que, a partir do momento em que são admitidas naquele centro de saúde, são despersonalizadas, assujeitadas, objetificadas (Leila Regina WOLFF; Maria Aparecida Vasconcelos MOURA, 2004; Tonia COSTA et al., 2006).

Essa objetificação, que enseja um maior controle dos corpos das mulheres (Maria Betânia AVILA, 2003), dá-se desde os procedimentos de padronização do cerimonial de internação até a forma de falar com elas, e também de não falar, através da ausência de esclarecimentos sobre as condutas, procedimentos e exames realizados, sem que nada lhes seja explicado. "Ninguém me dizia nada. Não falavam nada, eu era uma coisa e estavam fazendo coisas comigo" (Celina, parturiente).

Essa omissão nos esclarecimentos, além de partir do pressuposto de que o(a) profissional é o detentor do conhecimento e que, portanto, não precisa explicar nem justificar suas condutas ao "paciente", atua de maneira a, simbolicamente, colocar esta usuária no "seu lugar", que "é o da espera, o da falta, o da não informação sobre o que se procura no seu corpo, pois, a partir da entrada nos rituais hospitalares, esse corpo não mais pertence ao seu dono" (Wilza Rocha PEREIRA, 2004, p. 398).

Um monte de gente dentro da sala, um monte de aluno, um monte de luz, um frio infeliz [...] e todo mundo estava como se eu fosse um objeto ali em cima, pegando várias coisas [...] barulho [...] fazendo várias coisas e eu não queria nada. [...] elas não olhavam pra mim [...] não estavam nem aí para o que eu estava falando (Celina, parturiente).

Celina nos mostra ainda outra face da objetificação, que é a sensação de invisibilidade que essas mulheres vivenciam dentro da maternidade. Além de se sentirem como coisas, e, no caso das doulas, verem as mulheres serem tratadas assim, algo muito marcante em todos os relatos foi o fato de as mulheres não serem ouvidas, não terem suas dúvidas respondidas, de não serem tratadas de forma digna e respeitosa.

Sentir que não está sendo ouvida, que nada do que você está falando está sendo considerado, reforça a legitimidade e a sujeição que envolvem essa relação assimétrica entre médico(a) e demais profissionais da saúde e as usuárias desse sistema. Denota a redução daquela mulher a um órgão fragmentado, sem corpo, sem voz, sem identidade, desqualificada para questionar o saber técnico daquele que detém o poder naquele lugar (Emerson Elias MERHY, 2013).

Segundo Reis et al. (2017), o modelo de assistência obstétrica predominante no Brasil baseia-se na existência de uma relação assimétrica entre profissional e parturiente, o que se materializa na cena do parto, pois, mesmo quando a mulher participa, é para colaborar com o trabalho do profissional e não para garantir o exercício de sua autonomia. Não lhe é permitido expor suas necessidades, e seus desejos são silenciados.

A doula Dora ressalta que

esse tipo de coisa resulta numa assistência péssima, porque você nem olha para o outro como gente, que tem desejos, tem vontade, tem direitos [...] quando a gente encontra alguém que respeita o mínimo, dá um alívio,

de maneira a reforçar esta conduta como rotineira no contexto hospitalar.

Essa invisibilidade da mulher como sujeito, a qual é submetida desde os procedimentos de admissão na maternidade, é reforçada quando da sua exposição como objeto de cuidado. Sua intimidade, seus órgãos sexuais são expostos como parte dessa despersonalização e da falta de domínio sobre o seu corpo (DINIZ et al., 2015; Janaina Marques de AGUIAR et al., 2013).

Além da exposição de que fala Celina, a narrativa de Quitéria nos coloca diante de uma realidade que leva as pessoas a, de certa forma, assistirem às suas dores, ao seu trabalho de parto, como se assistissem a um espetáculo. Olhando, mas sem se envolver com a protagonista da cena.

Nessa gestão do poder, na contraposição entre a espetacularização e a invisibilidade, as mulheres se tornam visíveis como objeto. Como nos disse Dandara, "às vezes apareciam outras enfermeiras e abriam a cortina, [...] chega alguém, abre e sai, parece que é um espetáculo". Em contraponto, há a invisibilidade que elas enfrentam enquanto sujeitos: "ninguém olhava nos 
olhos, ninguém perguntava se eu estava bem, ninguém perguntava nada, eu não era uma pessoa, era uma coisa, um objeto".

Diante das narrativas aqui descritas, o ouvir, que deveria ser, como disse Merhy (2013), uma condição para o estabelecimento da relação entre a pessoa e equipe profissional, passa a ser enxergado como excepcionalidade, ao ponto de que encontrar um profissional que respeita o mínimo e escuta a parturiente é encarado com alívio.

\section{O exercício da autonomia: um direito ou um desacato?}

Sabemos que o termo autonomia possui uma gama de implicações éticas, políticas e sociais, contudo, ao nos atermos ao significado literal da palavra (auto: próprio; nomos: norma, regra, lei), somos remetidos à ideia de regras próprias, livre decisão, de comando de suas próprias ações, possibilidade de fazer suas escolhas.

Pereira (2004), citando Bourdieu, traz o significado de autonomia como sendo a faculdade de se governar por si mesmo ou, ainda, a liberdade ou independência moral ou intelectual, diferenciando-o do conceito de heteronomia, que é a condição de pessoa ou de grupo que recebe de um elemento que lhe é exterior, ou de um princípio estranho a si, a lei a que se deve submeter.

A apropriação dos saberes e práticas, trazida pelo processo de hospitalização do parto, conduz à manutenção de certo poder por parte dos médicos e demais profissionais de saúde, tornando a relação entre eles e as usuárias de saúde algo muito assimétrico, desigual. Propicia, assim, uma aproximação muito maior com a heteronomia do que com a autonomia (PEREIRA, 2004).

Porque quando vem uma pessoa, uma figura médica, principalmente, que tem muita autoridade, e diz que ela tem que ficar daquele jeito, numa sala toda equipada, num ambiente que não é o dela [...] então ela acaba ficando do jeito que querem que ela fique mesmo, ela não tem essa noção [de] que ela pode escolher (Leolinda, doula).

Esse excerto da fala da doula Leolinda nos mostra o quanto é difícil para as mulheres fazer escolhas ou buscar o cumprimento de suas vontades quando estão diante da autoridade ostentada pela equipe de saúde, diante de tantos equipamentos e em um lugar que para elas é desconhecido.

A autonomia, portanto, não é algo que você busca e, ao encontrar, passa a fazer suas próprias escolhas e fazer valer seus direitos e desejos. É preciso que existam condições para que esta autonomia seja exercida de maneira efetiva (REIS et al., 2017; Andréa Lorena Santos SILVA et al., 2015). Quando a mulher é despersonalizada e objetificada, as condições para que ela expresse sua autonomia naquele ambiente tendem a ser anuladas.

Chegou uma equipe do plantão com uma enfermeira muito ignorante, eram umas seis pessoas, e aí ela chegou e disse que tinha que fazer o toque. 'Não precisa, não quero!'. Ela disse: 'você não tem opção, a gente precisa ver como você está' [...] Sua bolsa não estourou ainda e a gente precisa estourar. Eu disse que estava tranquila, que não queria que estourassem [...] Ela disse: Ótimo! Fique aqui sozinha. Você vai parir aqui sozinha igual uma indigente (Celina, parturiente).

As palavras de Celina nos levam ao cenário mais inóspito para que qualquer pessoa exerça sua autonomia. Um lugar onde você "não tem opção". Ou você acata as ordens emanadas pelos profissionais de saúde ou "vai parir sozinha igual uma indigente" [sic].

Como podemos notar, esse poder se manifesta, nos hospitais, e mais especificadamente na maternidade em tela, através da presença marcante da hierarquia e disciplina, em que a hierarquia pressupõe superioridade, que, por sua vez, enseja subserviência e acatamento de ordens. Logo, não abre possibilidades para que a mulher venha a se contrapor à opinião da equipe de saúde, não podendo questionar a autoridade de seus componentes.

E aí, assim que eu sentei na cama, eu peguei na mão do doutor e disse: por favor, eu trouxe meu plano de parto, eu não quero que faça isso, isso, aquilo [...] E ele disse: Olha, você não tem que me ensinar a fazer o que eu estudei a vida inteira, eu vou fazer o que for necessário (Celina, parturiente).

Frases como "eu estudei a vida inteira", "Você não tem que me dizer o que fazer", "Eu faço isso há 30 anos" denotam como a ideia de autoridade médica, de superioridade centrada no saber, desequilibram a balança das relações entre médico e parturiente. Os profissionais exercitam o poder do saber como um lugar de legitimação institucional, que reafirma a forma de se relacionarem com as parturientes e ignoram o conhecimento e vontades delas (Claudia Mara PEDROSA; Mary Jane Paris SPINK, 201 1; TESSER, 2009).

Os estudos na área da saúde, no entanto, relatam que a autonomia deve ser considerada categoria norteadora e conteúdo central da promoção de saúde, reforçando que a restrição dessa autonomia atua como fator de risco elementar na cadeia causal dos principais grupos de agravos e patologias, terminando por gerar uma regressão estrutural do nível de saúde (PEREIRA, 2004; Paulo FLEURY-TEIXEIRA et al., 2008). 
Não restam dúvidas de que a informação e o empoderamento da mulher são importantes ferramentas na retomada da autonomia de seu corpo e de suas vontades. Corroborando este entendimento, o Ministério da Saúde diz: "há a necessidade da informação e formação de opinião entre as mulheres, para que elas possam reivindicar aquilo que seja mais benéfico para a sua saúde e a de seus filhos" (BRASIL, 2001, p. 35).

As três parturientes entrevistadas neste trabalho, cientes dessa necessidade, participaram de rodas de conversas e apoio à gestação e ao parto humanizado, informaram-se, construíram plano de parto, que se caracteriza por um documento em que as parturientes listam as condições em que desejam vivenciar seus partos, destacando os procedimentos cuja realização autorizam ou não. Duas delas tinham plano de saúde e ainda assim optaram por parir em maternidade pública por acreditarem ter mais chances de fazer nascer seus filhos através de um parto normal respeitoso. Contudo, essas condutas não foram suficientes para garantir o exercício de suas autonomias. Elas foram vitimadas. Pelas pessoas, pelo sistema obstétrico brasileiro e pela sociedade que as coisifica e as silencia.

A análise dos relatos demonstra que o fato de estarem informadas e de não aceitarem procedimentos desnecessários e invasivos as tornaram alvo de retaliações e rechaço por parte da equipe profissional.

Eu disse não, não quero, não vou sair daqui. E ela disse para o meu marido: 'Olha só, pai, se ela continuar desse jeito aí eu não vou fazer mais nada, não vou mais tocar nela'. [...] Como eu tinha plano de parto foram me deixando lá, como se fosse um desprezo. Era como se fosse muita pretensão minha levar um plano de parto para dizer a eles o que fazer [...] Tratavam quem não tinha informação como se a pessoa fosse imbecil: 'mãezinha, é assim mesmo, dói assim mesmo'. E comigo era desprezo! (Dandara, parturiente).

A leitura que Dandara consegue fazer é a de que, na visão deles, fora muita pretensão sua levar um plano de parto, ousar dizer à equipe profissional o que eles deveriam fazer. O plano de parto não servira como instrumento garantidor de suas vontades, do que queria que fizessem ou não com seu corpo. Pelo contrário, o fato de ousar levar um plano de parto fora motivo para que a deixassem sem assistência, desprezada.

Através desses relatos, é possível visualizar que ter informações por si só não é, e não foi, suficiente para não ser vítima da violência obstétrica. Conhecimento não garantiu, conforme demonstrado no presente estudo, o exercício da autonomia. Pelo contrário, aumentou a discussão sobre os planos de cuidado. Quando questionada, a equipe médica parece ter sido desafiada em sua autoridade e isso pôde gerar uma contrarresistência ainda mais violenta do que quando a mulher fica mais passiva.

Isto pode ser mais uma vez identificado quando Quitéria relata ter ouvido de uma médica que se tivesse aceitado a episiotomia não estaria com sua vagina toda rasgada - laceração que ocorrera, segundo ela, devido aos médicos terem alargado sua vagina com as mãos.

Na narrativa de Dandara foi possível registrar uma frase que, de certa forma, resume o impacto das violências sofridas nas mulheres. A dor vivenciada por elas termina por cortar mais do que a carne, deixar mais do que uma lembrança ruim. "Ela (a médica) tinha feito um corte na minha alma, pra eu levar pro resto da minha vida".

\section{"Uma episio só para ensinar": a maternidade-escola como cenário da violência naturalizada}

Ao longo do tempo, vêm sendo produzidos estudos que mostram a necessidade de desconstrução da ideia de isolamento e superioridade dos profissionais de saúde frente aos usuários. O encontro entre o trabalhador e o usuário da saúde deve ser produzido através da formação de um espaço comum, que preze pela intercessão dos saberes desses dois polos da relação. Nesse espaço comum, deve haver a intervenção das duas partes, convergindo esforços para a produção do cuidado (MERHY, 2013).

Os processos produtivos de saúde só podem se realizar nas intercessões entre trabalhador e usuário, sendo nesse encontro entre eles "que se dá, em última instância, um dos momentos mais singulares do processo de trabalho em saúde enquanto produtor de cuidado" (MERHY, 2013, p. 5).

Muito embora haja esse esforço para que o cuidado se alie ao saber técnico, focando as condutas médicas em menos intervenções e mais acolhimento, a realidade confrontada por este trabalho mostrou que as mulheres atendidas no hospital, no momento do parto, estão muito longe de conseguir interferir de alguma maneira no plano de cuidado a que são submetidas.

Foi possível constatar que muitas das condutas perpetradas pela equipe profissional são aprendidas e naturalizadas desde a formação desses profissionais. Como já mencionado neste trabalho, a maternidade " $X$ " é uma maternidade-escola. O que significa que alunos de medicina, fisioterapia e enfermagem são submetidos a um estágio prático-profissional, na instituição, supervisionado por seus docentes e preceptores. 
Os procedimentos são realizados como estratégia de ensino, sendo, por vezes, executados apenas para treinamento, de formas repetidas e desnecessárias clinicamente. Dessa maneira, 0 corpo da mulher é reduzido à condição de objeto de estudo, sem sua anuência e sem que lhe seja nem explicado o procedimento a ser realizado.

Eu já vi estudantes naquela cena sem interagir com a mulher, o que eu acho muito estranho. Aí ficam ali numa conversa entre o médico e os estudantes, discutindo, debatendo, olhando a dilatação. E ninguém se dá ao trabalho de pedir licença, falar com essa mulher (Leolinda, doula).

Ao agirem como se estivessem ministrando uma aula, falando e explicando procedimentos para os(as) acadêmicos(as), usando o corpo da mulher, os(as) médicos(as) preceptores(as) naturalizam a violência e ensinam aos estudantes uma prática que não cuida, não valoriza e não se importa com a individualidade daquela mulher (DINIZ et al., 2016; Sônia Nussenzweig HOTIMSKY, 2007).

E aí eles fazem um toque sem nem dizer o que é, e conversam com os alunos como se estivessem realmente dando uma aula e aí é que você se sente objeto. Porque ele não fala com você, ele fala com os alunos. Eu fiquei sabendo que eu estava com $10 \mathrm{~cm}$ (de dilatação) porque ele disse isso aos alunos (Celina, parturiente).

A objetificação do corpo, a invisibilidade da subjetividade e os procedimentos desnecessários são não apenas reproduzidos, mas ensinados aos novos profissionais de maneira naturalizada. Realizar uma episiotomia, procedimento cirúrgico no qual a vagina é cortada com um bisturi ou tesoura, e que pode trazer sérias consequências físicas e psicológicas para a mulher, apenas como forma "didática" de ensino, é cruel e de uma violência difícil de mensurar. "Quando eu cheguei na maternidade percebi que a episiotomia era quase que feita sequencialmente. Às vezes, fazem uma 'episio' só para ensinar" (Dora, doula).

Outro procedimento comumente ensinado aos estudantes por seus preceptores, por meio de várias repetições desnecessárias, é o toque vaginal. Este, apesar de doloroso para a mulher, é reproduzido por médicos(as) e acadêmicos(as) de forma indiscriminada, utilizando a mulhercorpo como 'cobaia' para treinamento. Cenas que reproduzem a construção de corpos-cobaias são relatadas por Celina, que passou pela experiência de ter seu corpo utilizado como instrumento para a aula prática de estudantes.

Tinha uns vinte alunos ao meu redor observando o professor mostrando como é que fazia o toque. [...] Eu me levantei e vi aquele monte de sangue em cima de mim eu pensava 'meu Deus, o que tá acontecendo comigo? O que tá acontecendo aqui?' (Celina, parturiente).

A realização de procedimentos desnecessários como condutas repassadas por preceptores a estudantes nos remete a uma formação iatrogênica, na qual se ensina a intervir ainda que não seja necessário. Aprende-se que precisa agir intrusivamente quando a única coisa que se esperaria dele seria empatia e atenção (HOTIMSKY, 2007; HOTIMSKY; Lilia Blima SCHRAIBER, 2005).

Dora nos relatou que um dos acompanhamentos que fez como doula na maternidade " $X$ " foi um dos momentos mais traumáticos que já viveu. "Nesse dia saí de lá e chorei por horas". A parturiente que ela acompanhava sofreu toda sorte de violências físicas e psicológicas na presença e com a ajuda de estudantes que estavam ali para aprender sobre cuidado em saúde.

A sala estava cheia nesse dia, foi horrivel. Porque tinham muitos estudantes, estava cheia, parecia uma algazarra, uma coisa horrorosa. Fizeram Kristeller, episiotomia [...] E essa mulher esgotada. [...] Posso dizer que foi umas das maiores demonstrações de falta de amor ao próximo que eu já vi (Dora, doula).

O código de ética médica brasileiro preconiza que são condutas vedadas ao médico:

Art. 22 Deixar de obter consentimento do paciente ou de seu representante legal após esclarecê-lo sobre o procedimento a ser realizado, salvo em caso de risco iminente de morte.

Art. 24 Deixar de garantir ao paciente o exercício do direito de decidir livremente sobre sua pessoa ou seu bem-estar, bem como exercer sua autoridade para limitá-lo.

Art. 31 Desrespeitar o direito do paciente ou de seu representante legal de decidir livremente sobre a execução de práticas diagnósticas ou terapêuticas, salvo em caso de iminente risco de morte (CFM, 2009 [grifos nossos]).

Nessa perspectiva, as mulheres demandam, na assistência ao parto, muito mais do que a garantia de suas vidas e a entrega de um filho saudável. Reivindicam uma assistência respeitosa e colaborativa entre profissionais e usuárias, na qual tenham voz ativa para discutir um plano de cuidado e as intervenções a que são submetidas (Raquel SIMAS; Sara Souza MENDONÇA, 2017; OMS, 2018). 


\section{Conclusões}

As relações de gênero foram observadas, neste estudo, através da objetificação do corpo da mulher; das relações de poder e hierarquização entre a mulher e os/as profissionais; da anulação do exercício de sua autonomia; da violência que aparece como característica das práticas médicas, e, ainda, através do tratamento que é dispensado às mulheres quando elas "ousam" discordar de algum procedimento da equipe de saúde.

Informação e empoderamento, apesar de elementos cruciais, na pauta da humanização do parto não foram suficientes para garantir que essas mulheres não fossem violentadas na assistência ao parto. Pelo contrário, a autonomia e o desejo de decidir como seria o seu parto, processo fisiológico em primazia, resguardadas as exceções, foram vistas como desacato, punidas com abandono e retaliação pelos profissionais. A informação, que deveria ter sido ferramenta para garantia de direitos, funcionou para instrumentalizar a violência.

Todavia, não acreditamos que a mudança deste cenário esteja na ignorância e apatia. Muito pelo contrário; se dará através da união de esforços para mudança na formação dos futuros profissionais, assim como na denúncia e visibilização dos casos de violência para que deixem de ser naturalizados e passem a ser encarados como violações ao direito da mulher à sua integridade corporal e condição de pessoa.

\section{Referências}

AMORIM, Melania; COUTINHO, Isabela Cristina; MELO, Inês; KATZ, Leila. "Episiotomia seletiva vs. implementação de um protocolo não-episiotomia: um ensaio clínico randomizado". Reprod. Health, v. 14, n. 55, p. 2-10, 2017.

AVILA, Maria Betânia. "Direitos sexuais e reprodutivos: desafios para as políticas de saúde". Cadernos de Saúde Pública, Rio de Janeiro, v. 19, supl. 2, p. S465-S469, 2003.

AGUIAR, Janaina Marques de; D'OLIVEIRA, Ana Flávia Pires Lucas; SCHRAIBER, Lilia Blima. “Institutional violence, medical authority, and power relations in maternity hospitals from the perspective of health workers". Cadernos de Saúde Pública, v. 29, n. 11, p. 2287-2296, 2013.

BRASIL. Parto, aborto e puerpério: assistência humanizada à mulher. Secretaria de Políticas de Saúde, Área Técnica da Mulher. Brasília, DF: Ministério da Saúde, 2001.

CONSELHO FEDERAL DE MEDICINA. Código de ética médica: Resolução CFM n 1.931/09. Brasília: CFM, 2009. p. 0103-5371.

COSTA, Tonia et al. "Naturalização e medicalização do corpo feminino: o controle social por meio da reprodução". Interface - Comunicação, Saúde, Educação, v. 10, p. 363-380, 2006.

DAVIS-FLOYD, Robbie. Birth as an american rite of passage. 1.ed. Berkeley; London: University of California Press, 1992.

DAVIS-FLOYD, Robbie; SAINT JOHN, Gloria. The technocratic model of medicine from doctor to healer. The transformative journey. New Bruswick: Rutgers University Press, 1998. p. 15-48.

DINIZ, Carmen Simone Grilo et al. "A vagina-escola: seminário interdisciplinar sobre violência contra a mulher no ensino das profissões de saúde". Interface-Comunicação, Saúde, Educação, v. 20, p. 253-259, 2016.

DINIZ, Carmen Simone Grilo. "Humanização da assistência ao parto no Brasil: os muitos sentidos de um movimento". Ciência \& Saúde Coletiva, v. 10, p. 627-637, 2005.

DINIZ, Carmen Simone Grilo et al. "Abuse and disrespect in childbirth care as a public health issue in Brazil: origins, definitions, impacts on maternal health, and proposals for its prevention". Journal of Human Growth and Development, v. 25, n. 3, p. 377-382, 2015.

FLEURY-TEIXEIRA, Paulo et al. "Autonomia como categoria central no conceito de promoção de saúde". Ciência \& Saúde Coletiva, v. 13, n. supl 2, p. 2115-2122, 2008.

HOTIMSKY, Sonia Nussenzweig. A formação em obstetrícia: competência e cuidado na atenção ao parto. 2007. Tese (Doutorado) - Universidade de São Paulo, São Paulo.

HOTIMSKY, Sonia Nussenzweig; SCHRAIBER, Lilia Blima. "Humanização no contexto da formação em obstetrícia”. Ciência \& Saúde Coletiva, v. 10, p. 639-649, 2005. 
LEÃO, Míriam Rêgo de Castro; BASTOS, Marisa Antonini Ribeiro. "Doulas apoiando mulheres durante o trabalho de parto: experiência do Hospital Sofia Feldman". Revista Latino-Americana de Enfermagem, v. 9, n. 3, p. 90-94, 2001.

MERHY, Emerson Elias. "O cuidado é um acontecimento e não um ato". In: FRANCO, Túlio Batista; MERHY, Emerson Elias. Trabalho, produção do cuidado e subjetividade em saúde. Textos Reunidos. São Paulo: Hucitec, 2013.

MINAYO, Maria Cecília de Souza et al. Pesquisa Social: Teoria, método e criatividade. 16. ed. Petrópolis: Editora Vozes, 2008.

NAGAHAMA, Elizabeth Eriko Ishida; SANTIAGO, Silvia Maria. "A institucionalização médica do parto no Brasil". Ciência \& Saúde Coletiva, v. 10, p. 651-657, 2005.

OMS. Recomendação da OMS sobre política de episiotomia. Genebra: Biblioteca da Saúde Reprodutiva da OMS, 2018.

PEDROSA, Claudia Mara; SPINK, Mary Jane Paris. "A Violência Contra Mulher no Cotidiano dos Serviços de Saúde: desafios para a formação médica". Saúde e Sociedade, v. 20, n. 1, p. 124-135, 2011.

PEREIRA, Wilza Rocha. "Poder, violência e dominação simbólicas nos serviços públicos de saúde". Texto \& Contexto-Enfermagem, v. 13, n. 3, 2004.

RIESSMAN, Catherine Kohler. Narrative methods for the human sciences. Thousand Oaks: Sage, 2008.

REIS, Thamiza da Rosa dos et al. "Autonomia feminina no processo de parto e nascimento: revisão integrativa da literatura". Revista Gaúcha de Enfermagem, v. 38, n. 1, 2017.

RIESCO, Maria Luiza Gonzalez. "Nascer no Brasil 'em tempo': uma questão de hierarquia das intervenções no parto?". Cadernos de Saúde Pública, v. 30, p. S35-S36, 2014.

SAFFIOTI, Heleieth. "Contribuições feministas para o estudo da violência de gênero". Cadernos Pagu, v. 16, p. 115-136, 2001.

SAFFIOTI, Heleieth. Gênero, patriarcado, violência. 2. ed. São Paulo: Expressão Popular; Fundação Perseu Abramo, 2015.

SENA, Ligia Moreiras; TESSER, Charles Dalcanale. "Violência obstétrica no Brasil e o ciberativismo de mulheres mães: relato de duas experiências". Interface - Comunicação, Saúde, Educação, v. 21 , p. 209-220, 2016.

SILVA, Andréa Lorena Santos; NASCIMENTO, Enilda Rosendo do; COELHO, Edméia De Almeida Cardoso. "Práticas de enfermeiras para promoção da dignificação, participação e autonomia de mulheres no parto normal". Escola Anna Nery, v. 19, n. 3, p. 424-431, 2015.

SIMAS, Raquel; MENDONÇA, Sara Souza. "O caso Adelir e o movimento pela humanização do parto: reflexões sobre violência, poder e direito". Vivência: Revista de Antropologia, v. 1, n. 48, p. 89-103, 2017.

SOUZA, Aline Barros de et al. "Fatores associados à ocorrência de violência obstétrica institucional: uma revisão integrativa da literatura". Revista de Ciências Médicas, v. 25, n. 3, p. 115-128, 2017.

TESSER, Charles Dalcanale et al. "Violência obstétrica e prevenção quaternária: o que é e o que fazer". Revista Brasileira de Medicina de Família e Comunidade, v. 10, n. 35, p. 1-12, 2015.

TESSER, Charles Dalcanale. "Three considerations about 'bad medicine'”. Interface - Comunicação, Saúde, Educação, v. 13, n. 31, p. 273-286, 2009.

WOLFF, Leila Regina; MOURA, Maria Aparecida Vasconcelos. "A institucionalização do parto e a humanização da assistência: revisão de literatura". Escola Anna Nery Revista de Enfermagem, v. 8, n. 2, p. 279-285, 2004.

Juliana Sampaio (julianasmp@hotmail.com) é doutora em Saúde Pública, Líder do Grupo de Pesquisa Política, Educação e Cuidado em Saúde (GPECS). Professora da Graduação de Medicina, Mestrado em Saúde Coletiva e Programa de Pós-Graduação Modelos de Decisão em Saúde. Experiência com os temas: atenção básica, gestão do cuidado, políticas públicas, saúde mental, direitos sexuais e reprodutivos e gênero. 
Tatiana Lopes de Albuquerque Tavares (tatianalopesatavares@hotmail.com) é ativista pela humanização do parto. Graduada em Segurança Pública pela Academia de Polícia Militar do Cabo Branco (2010), especialista em Segurança Pública e Direitos Humanos pela Universidade Federal da Paraíba (2015) e em Gestão Pública pelo Instituto Federal da Paraíba (2017), possui Bacharelado em Direito pela Universidade Federal da Paraíba (2017).

Thuany Bento Herculano (thuany_herc@hotmail.com) é graduada em Medicina pela Universidade Federal da Paraíba. Residente em Ginecologia e Obstetrícia pela Faculdade de Ciências Médicas da Unicamp. Experiência com os temas: humanização do parto e nascimento e contracepção reversível de longa duração.

\section{COMO CITAR ESSE ARTIGO DE ACORDO COM AS NORMAS DA REVISTA}

SAMPAIO, Juliana; TAVARES, Tatiana Lopes de Albuquerque; HERCULANO, Thuany Bento. "Um corte na alma: como parturientes e doulas significam a violência obstétrica que experienciam". Revista Estudos Feministas, Florianópolis, v. 27, n. 3, e56406, 2019.

\section{CONTRIBUIÇÃO DE AUTORIA}

Juliana Sampaio: Concepção do estudo, análise de dados e elaboração do manuscrito.

Tatiana Lopes de Albuquerque Tavares: Concepção do estudo, coleta e análise de dados, elaboração do manuscrito, redação, discussão de resultados.

Thuany Bento Herculano: Concepção do estudo, análise dos dados, redação e discussão dos resultados.

\section{FINANCIAMENTO}

Não se aplica.

\section{CONSENTIMENTO DE USO DE IMAGEM}

Não se aplica.

APROVAÇÃO DE COMITÊ DE ÉTICA EM PESQUISA

O estudo foi aprovado pelo Comitê de Ética do Centro de Ciências da Saúde da UFPB sob CAAE: 67650617.0 .0000 .5188

\section{CONFLITO DE INTERESSES}

Não se aplica.

\section{LICENÇA DE USO}

Este artigo está licenciado sob a Licença Creative Commons CC-BY Internacional. Com essa licença você pode compartilhar, adaptar, criar para qualquer fim, desde que atribua a autoria da obra.

\section{HISTÓRICO}

Recebido em 16/04/2018

Reapresentado em 20/12/2018

Aprovado em 03/04/2019 